\title{
PRINCÍPIOS DO DESENHO DIDÁTICO DA EDUCAÇÃO ONLINE
}

\section{DIDACTIC DESIGN PRINCIPLES OF ONLINE EDUCATION}

\section{PRINCIPIOS DEL DISEÑO DIDÁCTICO DE LA EDUCACIÓN ONLINE}

Mariano Pimentel ${ }^{1}$

RESUMO: No presente artigo, apresento os resultados de uma pesquisa-ação realizada na disciplina "Informática na Educação" do curso de Licenciatura em Pedagogia a Distância da UNIRIO/CEDERJ/UAB. O desenho didático dessa disciplina estava inicialmente baseado no modelo de educação massiva e instrucionista. Ao longo de uma década, fui transformando o desenho didático buscando promover uma educação online baseada nas práticas da cibercultura. Como resultado, foram identificados seis princípios que guiaram as ações efetivadas na disciplina: (a) uso de diferentes sistemas computacionais; (b) interatividade e colaboração; (c) ênfase na autoria e nas atividades práticas; (d) avaliação formativa; (e) tutoria ativa; e (f) curadoria de conteúdos online. A experiência vivenciada, somada às percepções de alunos e professores-tutores sobre as modificações efetivadas na disciplina, ratificaram a importância do desenho didático proposto em que o aluno ganha protagonismo como produtor de conhecimentos.

Palavras-chave: Desenho Didático. Educação a distância. Educação online. Cibercultura.

Submetido em: 30/07/2018 - Aceito em: 20/12/2018 - Publicado em: 26/01/2019

${ }^{1}$ Doutor em Informática pela PUC-Rio (2006), Mestre em Informática pelo NCE-UFRJ (2002), e Bacharel em Informática pela UFRJ (1999). Professor Associado do Departamento de Informática Aplicada da UNIRIO, leciona disciplinas na PósGraduação em Informática ( Docência em Sistemas de Informação, Design Science Research, Sistemas Colaborativos, Metodologia de Pesquisa Científica), no Bacharelado em Sistemas de Informação (WebDesign, Informática na Educação) e na Licenciatura em Pedagogia a Distância (Informática na Educação). Tem extensa produção acadêmica, destacando-se o livro "Sistemas Colaborativos" (2011), que recebeu o Prêmio Jabuti; e seu mais recente livro "Do email ao Facebook". É coordenador do grupo de pesquisa ComunicaTEC, focado no desenvolvimento do projeto "Tagarelas: rede social de bate-papo". É colaborador no grupo de pesquisa GPDOC - Grupo de Pesquisa Docência e Cibercultura, do ProPEd/UERJ. Realiza pesquisas na área de Sistemas de Informação com ênfase em Sistemas de Conversação (bate-papo, fórum, microblog etc.) aplicados a Educação Online. 
ABSTRACT: In this article, I present the results of an action-research carried out in the discipline Computers in Education of UNIRIO / CEDERJ / UAB. The didactic design of this discipline was initially based on the model of massive and instructional education. Over a decade, I was transforming the didactic design to promote an online education based on the practices of cyberculture. As a result, six principles that guided the actions carried out in the discipline were identified: (a) use of different computational systems; (b) interactivity and collaboration; (c) emphasis on authorship and practical activities; (d) formative assessment; (e) active mentoring; and (f) curation of online content. Experience coupled with the perceptions of students and teacher-tutors about the modifications undergone in the discipline, ratified the importance of the proposed didactic design in which the student gains protagonism as a producer of knowledge.

Keywords: Didactic Design. Distance education. Online education. Cyberculture.

RESUMÉN: En el presente artículo, presento los resultados de una investigación-acción realizada en la disciplina "Informática en la Educación" del curso de Licenciatura en Pedagogía a Distancia de la UNIRIO / CEDERJ / UAB. El diseño didáctico de esta disciplina estaba inicialmente basado en el modelo de educación instruccional y masiva. Durante una década, fui transformando el diseño didáctico buscando promover una educación en línea basada en las prácticas de la cibercultura. Como resultado, seis principios, que guiaron las acciones efectivas en la disciplina, fueron identificados: (a) uso de diferentes sistemas computacionales; (b) interactividad y colaboración; (c) énfasis en la autoría y en las actividades prácticas; (d) evaluación formativa de las actividades; (e) tutoría activa; y (f) curaduría de contenidos en línea. La experiencia vivenciada, sumada a las percepciones de alumnos y profesores-tutores sobre las modificaciones llevadas a cabo en la disciplina, ratificaron la importancia del diseño didáctico propuesto en que el alumno tiene protagonismo como productor de conocimientos.

Palabras clave: Diseño Didáctico. Educación a distancia. Educación en línea. Cibercultura.

\section{INTRODUÇÃO}

Nossa sociedade vem passando por profundas transformações. Nosso modo de ser e de estar em sociedade, nossos valores e costumes, vêm sendo reconfigurados junto a mudanças na economia, na política, no trabalho, na educação, na organização social, nas instituições e nos mais variados setores da vida. "O ser humano do século XXI tem novos comportamentos, novos estilos de ser e agir, lê e escreve de forma diferente, desenvolveu novas formar de pensar e aprender, de se relacionar com amigos e de amar" (NICOLACI-DA-COSTA; PIMENTEL, 2011, p. 3). A revolução que agora presenciamos é uma consequência do desenvolvimento dos computadores na década de 1950, das 


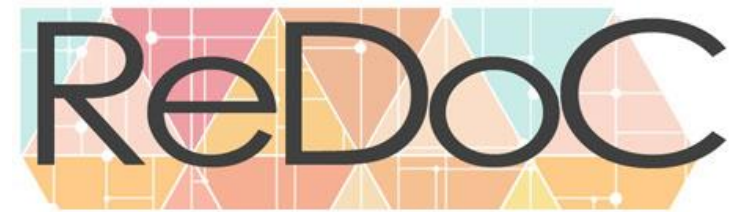

\section{Revista Docência e Cibercultura}

redes de computadores no final da década de 1960, da popularização dos microcomputadores na década de 1970 e 1980, da disseminação mundial da web e dos meios de conversação em rede na década de 1990, da disseminação da computação móvel e ubíqua principalmente a partir da década de 2000, e da enorme popularização dos sistemas digitais de redes sociais ocorrida principalmente na década de 2010. Essa infraestrutura tecnológica, composta de hardware e software, constitui o ciberespaço, o espaço de convivência da 'sociedade em rede' (CASTELLS, 1999), um espaço que atrai e mantém frequentadores vivenciando experiências com outros humanos e também com não-humanos. Dessa relação entre seres humanos e as tecnologias digitais em rede, emergem novas práticas e fenômenos sociotécnicos que caracterizam a nossa cultura contemporânea, a Cibercultura (LEVY, 1999; SANTOS, 2010).

Este novo cenário sociotécnico vem reconfigurando os processos educativos e fazendo emergir novos processos de ensino-aprendizagem como Educação a Distância mediada pela internet (EAD), MOOC (curso online aberto e massivo) e Educação Ubíqua (SANTAELLA, 2014). Contudo, esses processos educacionais não necessariamente estão alinhados com as práticas típicas da cibercultura, como buscar, navegar, conectar-se, compartilhar, curtir, comentar, interagir, postar, criar (autorias), dentre outras práticas. Precisamos (re)pensar a educação buscando uma aproximação das práticas pedagógicas com as práticas (ciber)culturais para que o processo educacional faça mais sentido para os educandos na contemporaneidade.

Em tempos de cibercultura (LEVY, 1999), eu, enquanto professor-pesquisador, sinto-me desafiado a repensar continuamente minha prática pedagógica. Venho apostando em projetos de aprendizagem (FAGUNDES; SATO; LAURINO, 1999) que possibilitam o aprender-fazendo com autoria (AMARAL, 2016), bem como na colaboração (FUKS et al., 2011) e interatividade (SILVA, 2000) que propiciam a aprendizagem colaborativa (TORRES, 2014) e em rede (SIEMENS, 2008). Contudo, admito que não é trivial efetivar uma prática docente alternativa à exposição de conteúdos, seja no presencial ou a distância. Estou continuamente me questionando se venho efetivamente promovendo a colaboração entre todos e em rede; ou se venho apenas dando uma nova roupagem à velha prática comunicacional unidirecional que, embora fazendo uso das tecnologias digitais em rede, ainda esteja centrada no professor aos moldes do 'ensino tradicional' que nos coloca no centro das atenções e nos faz desempenhar o papel de detentor de conhecimento (SANTOS; CARVALHO; PIMENTEL, 2016), lugar e papel que não quero estar nem desempenhar por considerá-los 


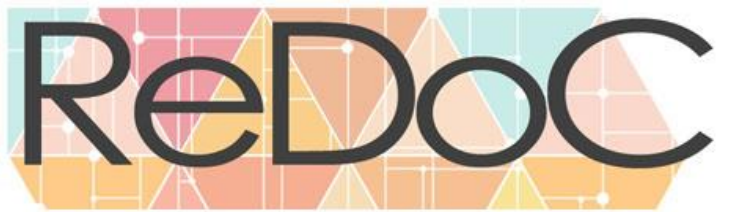

\section{Revista Docência e Cibercultura}

incompatíveis com os princípios da cibercultura (LEMOS, 2007). É a partir desse questionamento que desenvolvo todas as minhas pesquisas, como a que apresento neste artigo.

No presente artigo, apresento os resultados de uma pesquisa-ação realizada no âmbito da disciplina Informática na Educação do curso de Licenciatura em Pedagogia a Distância da UNIRIO/CEDERJ/UAB. O desenho didático dessa disciplina estava inicialmente baseado no modelo de educação massiva e instrucionista, conforme discuto na Seção 2. Ao longo de uma década, fui transformando o desenho didático da disciplina buscando promover uma educação online baseada nas práticas da cibercultura. Como sintetizo na Seção 3, identifico seis princípios que guiaram as ações efetivadas na disciplina visando a um desenho didático de educação online. A experiência vivenciada, somada às percepções de alunos e professores-tutores sobre as modificações realizadas na disciplina, ratificaram a importância do desenho didático proposto no qual o professor-tutor assume seu protagonismo enquanto docente que propicia a interatividade e a colaboração entre os aprendentes, e no qual os alunos ganham protagonismo como produtores de conhecimentos por meio de práticas que favorecem um modo de pensar aberto e flexível, que promovem a autonomia e a consciência do próprio processo de aprendizagem.

Com este artigo, objetivo denunciar a necessidade de mudanças no sistema de educação a distância de nosso país para viabilizar desenhos didáticos alternativos, e enunciar as possibilidades que investiguei no contexto de uma disciplina. Além de suscitar mudanças políticas, espero que o caso aqui relatado também possa inspirar outros docentes a repensar o desenho didático e suas práticas pedagógicas na modalidade a distância.

\section{REDESENHANDO UMA DISCIPLINA A DISTÂNCIA: ADOTANDO PRÁTICAS INSPIRADAS NA CIBERCULTURA}

Em 2007, fui convidado para atuar no papel de coordenador da disciplina Informática na Educação do curso de Pedagogia na modalidade a distância da UNIRIO/CEDERJ/UAB. Meu estranhamento já começou pela minha denominação: eu não seria um professor, mas sim um coordenador. Descobri que minha principal função era coordenar uma equipe de professores-tutores, sendo dois professores-tutores a distância que atuariam comigo na minha própria universidade, e vários professores-tutores presenciais que atuariam nos polos do município do estado do Rio de Janeiro. Na época atendíamos a 10 polos e naquele primeiro semestre letivo estavam matriculados 279 alunos na 


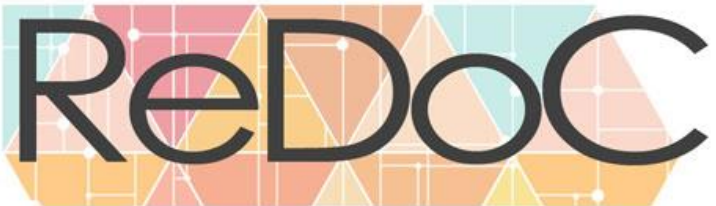

\section{Revista Docência e Cibercultura}

disciplina (quase 30 alunos por polo, em média) - nunca havia lecionado para tantos alunos de uma só vez.

Também estranhei o desenho didático, pois não era feito por mim, já estava parcialmente planejado e uniformizado para todas as disciplinas: provas bimestrais presenciais, denominadas Avaliação Presencial (AP), previamente agendadas pela coordenação do curso; estudo dirigido sobre os conteúdos bimestrais, valendo $20 \%$ da nota, denominado Avaliação a Distância (AD); e no caso particular da disciplina que eu coordenaria, também havia 5 aulas práticas em um 'laboratório de informática' que os alunos precisariam ter no mínimo $75 \%$ de frequência. Em minhas disciplinas presenciais, eu não usava a prova como instrumento de avaliação, mas descobri que, por lei, na modalidade a distância somos obrigados a realizar exames presenciais (BRASIL, 2005), o que me causou desconforto. Os conteúdos da disciplina também já estavam previamente definidos: eu deveria seguir um livro-texto escrito por outros professores (que desempenharam o papel de 'autorconteudista'), o que também me causou estranhamento, pois estava acostumado a selecionar os conteúdos em minhas disciplinas presenciais.

Pisando em terras estrangeiras, estranhando tudo, tentei me conformar com o instituído. Com a prática, fui descobrindo o trabalho que eu deveria fazer. Com relação ao desenho didático, cabia a mim apenas indicar quais capítulos do livro os estudantes deveriam estudar em cada semana, e deveria divulgar o 'Cronograma da Disciplina' no início do semestre sem poder modifica-lo ao longo do período, o que exigia um planejamento de tudo independentemente dos alunos, dos interesses e dificuldades deles - no presencial, contudo, não trabalho com Desenho Instrucional, mas sim com Atos de Currículo (MACEDO, 2013) construindo o currículo com os alunos, planejando cada aula em função da anterior (ainda que exista um planejamento global para a disciplina, mas é bastante flexível e negociável). Também cabia a mim elaborar as 'Avaliações' e preparar um 'Guia de Correção' orientando como os professores-tutores deveriam corrigir as avaliações. A mim e aos tutores a distância cabia corrigir, num prazo exíguo, vários pacotes contendo as provas feitas pelos alunos nas avaliações presenciais. Também havia algumas atividades extraclasse que eu precisava realizar, tais como: participar do processo de seleção de professores-tutores, promover 'capacitação' dos professores-tutores, e realizar visitas aos polos. Todas as atribuições que cabiam a mim, enquanto coordenador de disciplina, bem como o que cabia aos demais papéis (autor-conteudista, tutor a 


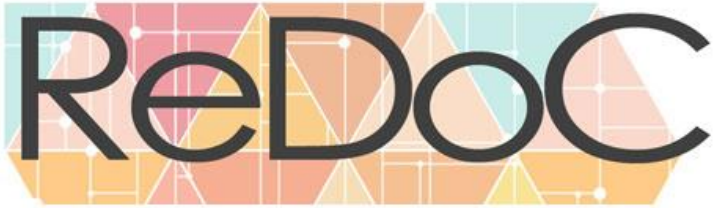

Revista Docência e Cibercultura

distância, tutor presencial etc.), estavam bem definidas e documentadas (FUNDAÇÃO CECIERJ, 2008).

Nos semestres seguintes, fui fazendo algumas ações pontuais para modificar o desenho didático da disciplina, dentro das normas e limites que eu reconhecida. Por exemplo, adotei um texto meu para a primeira aula em vez de um capítulo do livro-texto. Defini algumas atividades práticas a serem realizadas nas avaliações a distância, que os alunos poderiam efetivar nas aulas presenciais no laboratório de informática. Também tentei fazer uso dos meios de conversação disponíveis no Ambiente Virtual de Aprendizagem (AVA) do curso à época, embora eu tenha encontrado uma série de limitações e dificuldades que impossibilitaram a realização de fóruns e bate-papo como eu desejava para a disciplina. E não tinha muito mais o que inventar.

Fui percebendo, na prática, o processo de industrialização da Educação a Distância (EAD) denunciado por Belloni (2012, p.17-18):

\begin{abstract}
O modelo de EaD tem sido identificado com os modelos fordistas de produção industrial por apresentar as seguintes características principais: racionalização, divisão acentuada do trabalho, alto controle dos processos de trabalho, produção em massa de 'pacotes educacionais', concentração e centralização da produção, burocratização. As análises críticas dos autores referidos apontam seus principais aspectos negativos: desqualificação dos quadros acadêmicos e técnicos das instituições ('alienados' em processos de trabalho fragmentados e estandardizados), desumanização do ensino com a mediatização e burocratização das tarefas de ensino e aprendizagem.
\end{abstract}

Sentia-me em uma camisa de força trabalhando para um modelo instrucional com o qual eu não me identificava, tendo que realizar um trabalho padronizado e burocrático, sem autonomia para adotar outro desenho didático com outras práticas pedagógicas que eu considerava mais adequadas para a disciplina - o que também já havia sido denunciado por Lapa e Pretto (2010, p.79-80):

A disseminação do Sistema Universidade Aberta do Brasil (UAB) tem padronizado o
entendimento do trabalho docente na educação a distancia (EaD), a partir de uma concepção
dessa modalidade de ensino que preconiza uma educação de massa e a redução do trabalho
docente. (...) Se, por um lado, as instituições, inclusive (e principalmente) as públicas e
gratuitas, aderem ao empenho nacional de expansão e democratização do ensino superior na
formação de professores, por outro acabam legitimando a consolidação de um modelo de
educação que nem sempre condiz com suas perspectivas teóricas e suas práticas pedagógicas.
No que concerne ao professor, as diretrizes financeiras determinam também o papel docente 


\section{Revista Docência e Cibercultura}

na EaD. A docência, distribuída em diferentes papéis, como o de professor e o de tutor (a distância e presencial), está definida em resoluções que enquadram esses profissionais como bolsistas que sequer têm direito a uma declaração do trabalho que realizam como professores, devido à possível consolidação de vínculos empregatícios não desejados. (...) A conclusão é que essa política padroniza os projetos de cursos pela EaD e não acolhe propostas com outras concepções, eliminando, assim, a possibilidade de reconhecimento do trabalho profissional do professor na modalidade a distância.

Com o passar dos semestres, fui desacreditando dessa modalidade. Antes eu era um entusiasta da EAD porque, em minha experiência anterior em uma disciplina a distância, empregávamos uma abordagem socioconstrutivista com ênfase na colaboração entre os alunos efetivada por discussões em várias sessões de fóruns e de bate-papo, e por projeto de aprendizagem (LUCENA; FUKS, 2002). No curso em que agora estava trabalhando, estava imposta uma abordagem instrucionista que eu desacreditava e não me identificava enquanto docente.

Posteriormente, especialmente a partir dos estudos de Edméa Santos, compreendi a diferenciação conceitual entre as duas abordagens, sendo que ela denomina de Educação Online (EOL) o que eu havia praticado em minha experiência anterior, em diferenciação à Educação a Distância (EAD) que eu vinha praticando no curso em questão:

A educação online é o conjunto de ações de ensino e aprendizagem ou atos de currículo mediados por interfaces digitais que potencializam práticas comunicacionais interativas e hipertextuais. [...] Quando diferenciamos a educação a distância (EAD) da educação online, é uma tentativa de contextualizar e tratar a educação online de um lugar diferenciado. Do lugar de um contexto sócio-histórico e cultural, onde computador/internet são instrumentos culturais de aprendizagem [...]. A EAD é uma modalidade educacional historicamente mediada por mídias de massa (impressos, audiovisuais em geral), que não liberam o polo da emissão. Assim, os aprendentes interagem com o desenho e os materiais didáticos sem cocriar, juntamente com seus colegas e professores, o conhecimento. As mídias de massa não permitem interatividade no sentido do mais comunicacional, do cocriar a mensagem. Por conta do limite da mídia de massa, a modalidade a distância privilegia pedagogicamente os conceitos de 'autoaprendizagem' e 'autoestudo'. O sujeito interage com o material e aprende por esta mediação. A aprendizagem colaborativa não é vivenciada pelo aprendente. Neste modelo, a qualidade dos processos é centrada no desenho didático ou instrucional, geralmente instrucionistas. A interação social, quando acontece, é de um para um, ou seja, professor/aluno - aluno/professor. (SANTOS, E., 2010, p.37, 44) 


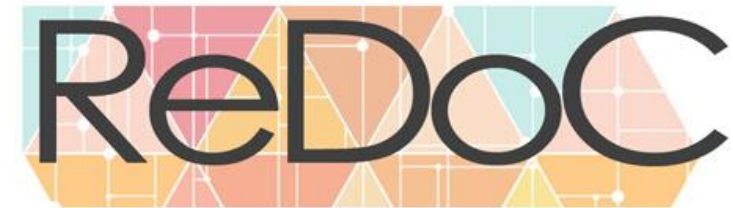

\section{Revista Docência e Cibercultura}

Com meu desinteresse pela disciplina também vieram os problemas: prazo que eu não cumpria para o lançamento de notas no sistema acadêmico, falhas na coordenação da equipe de professorestutores (que já percebiam meu desinteresse), e até queixas de alunos com problema na disciplina que eu não me empenhava em resolver.

O coordenador do curso me chamou para uma conversa. Expliquei que a disciplina estava na contramão de meus saberes docentes e de minhas práticas pedagógicas, que não estava acreditando na adequação daquele sistema de EAD, e assim coloquei minha bolsa à disposição. Ele retrucou que eu não deveria desistir, e sugeriu que eu mudasse o desenho didático para deixá-lo coerente com minha concepção de educação.

Com a autorização e o apoio do coordenador do curso à época, não desisti. A partir de 2010, comecei um processo de pesquisa-ação (BARBIER, 2007), tornando a disciplina também um campo para realizar minhas pesquisas em Cibercultura e em Sistemas de Informação. Um primeiro estudo foi a adoção de blog como meio para compartilhar as produções individuais e do coletivo de alunos em cada polo, pesquisa relatada por Marques, Pimentel e Siqueira (2011). Desde então, mantive-me investigando os efeitos da realização de ações, algumas até subversivas, em busca de um desenho didático inspirado em práticas da cibercultura (RIBEIRO; CARVALHO; SANTOS, 2018), entendendo "a educação online como obra aberta, plástica, fluida, hipertextual e interativa" (SANTOS; SILVA, 2009). Seria possível realizar uma educação online dentro de um sistema de educação a distância? Essa era a questão que mobilizou minhas ações e pesquisas na disciplina em questão, o que narro na próxima seção.

\section{PRINCÍPIOS}

Como mencionado anteriormente, o desenho didático da disciplina 'Informática na Educação' sofreu um processo de transição ao longo de uma década, passando de um modelo de desenho instrucionista-massivo (induzido pelo sistema de educação a distância) para um modelo de desenho didático baseado em práticas da cibercultura. Apresento, a seguir, seis princípios que guiaram as ações dessa reconfiguração. 


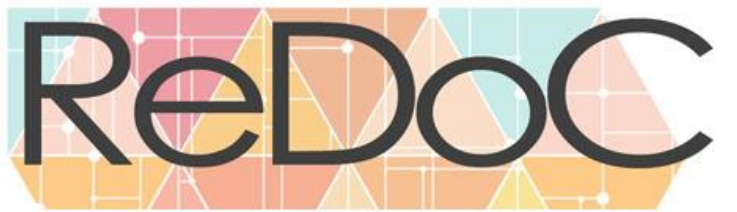

\section{Revista Docência e Cibercultura}

Em termos metodológicos, além da vivência no cotidiano da disciplina, da observação participante e da 'escuta sensível'2 (Barbier, 2007), ao final de alguns semestres letivos também aplicávamos um questionário de pesquisa sobre os princípios colocados em prática na disciplina, tendo em vista sistematizar as impressões e avaliações de alunos e professores-tutores. Os dados que seguem são relativos à edição da disciplina realizada no $1^{\circ}$ semestre de 2016. Do total de 299 alunos matriculados naquele semestre, 69 responderam ao questionário (23\% da população). Dos 15 professores-tutores da disciplina (sendo 2 professores-tutores a distância e 13 professores-tutores presenciais), 11 responderam ao questionário (73\% da população).

\section{USO DE DIFERENTES SISTEMAS COMPUTACIONAIS}

Para além do Ambiente Virtual de Aprendizagem (AVA) adotado oficialmente no curso (uma customização do Moodle), na disciplina adotamos diversos outros sistemas computacionais, como: Facebook, Instagram, WhatsApp, Google Drive e alguns editores. Quando perguntado aos alunos o que acharam sobre usar outros sistemas computacionais além do AVA, quase todos (93\% dos alunos respondentes) julgaram como sendo bom ou excelente. Este dado desmistificou a ideia de que um único sistema centralizador é o mais adequado para apoiar a realização de uma disciplina.

Poderíamos supor que os alunos só indicaram ser adequado o uso de outros sistemas computacionais porque estavam no contexto da disciplina Informática em Educação. Contudo, quando perguntado quais sistemas experienciados também poderiam ser usados em outras disciplinas, a maioria indicou: WhatsApp (73\%), Grupo do Facebook (70\%) e Google Drive (62\%), sendo que o Bate-papo do Facebook também foi indicado por muitos (42\%). Os demais sistemas não tiveram a indicação da maioria: 24\% indicaram o uso de Editor de História em Quadrinhos, 14\% indicaram o Editor de Memes, e apenas 6\% o Instagram. Alguns alunos também sugeriram o uso de outros tipos de sistemas que não chegaram a ser usados na disciplina, como Blog, Twitter e Skype.

Poderíamos supor, ainda, que ao menos os professores-tutores iriam preferir o uso de AVA por centralizar todo o trabalho em um único lugar. Contudo, os professores-tutores da disciplina apresentaram uma opinião ainda mais radical que os alunos, sendo que 37\% dos professores-tutores

\footnotetext{
${ }^{2}$ A escuta sensível, como prática dialógica, refere-se a um modo de tomar consciência e de interferir, em diferentes situações, com base na sensibilidade.
} 


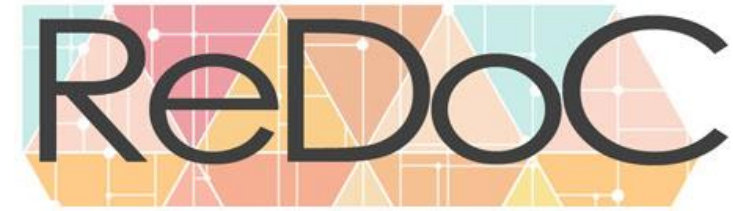

\section{Revista Docência e Cibercultura}

julgaram o AVA do curso como sendo ruim ou péssimo. Tanto os alunos quanto os tutores preferiram o Grupo do Facebook em vez do AVA do curso.

Estes dados são muito reveladores, pois indicam que alunos e tutores reconhecem a utilidade do uso de um repertório variado de sistemas computacionais, contrastando com a realidade de muitas disciplinas que desperdiçam a oportunidade de enriquecer a interação e a interatividade com o uso de outros sistemas e serviços para além dos que estão disponíveis na plataforma de aprendizagem adotada no curso. A grande ênfase que é dada para o uso de AVA acaba disseminando uma cultura de confinamento e exclusividade, a tal ponto que os professores chegam até a supor que seja proibido usar outros sistemas computacionais.

Em tempos de cibercultura, devemos nos apropriar de diferentes sistemas computacionais e serviços interativos online, como aplicativos, redes sociais, editores entre outros. Como ressaltado por Santos, Ribeiro e Carvalho (2018), o Moodle foi o ambiente de aprendizagem mais utilizado na $1^{\text {a }}$ fase da Educação Online, mas na atualidade também empregamos o uso de sistemas de redes sociais digitais, editores diversos, aplicativos e diversos outros sistemas computacionais.

\section{PROMOÇÃO DA INTERATIVIDADE E DA COLABORAÇÃO}

Queríamos valorizar não apenas a interatividade entre alunos e tutores, mas especialmente a interatividade dos alunos entre si. Promover interatividade e colaboração, bem como a autoria, são reinvindicações de longa data no campo da Educação, como diz Silva (2018, p. 15):

Costumo dizer: se estivessem vivos hoje e fossem incluídos ciberculturais, Paulo Freire, Vygotsky, Freinet, Dewey e Anísio Teixeira saberiam tomar a Web 2.0 ou a internet social e suas redes sociais como aliados capazes de materializar a ação comunicacional da educação autêntica, presencial e online, feita de conectividade, autoria, compartilhamento, colaboração, dialogia e interatividade.

Na educação a distância, é comum os alunos sentirem-se estudando sozinhos, o que é potencialmente um problema porque a percepção de isolamento é identificada como um dos fatores de evasão (FAVERO, 2006, p. 154): 


\title{
Revista Docência e Cibercultura
}

\begin{abstract}
Ao se sentirem parte do processo, ao perceberem que não estão sozinhos e que estão adquirindo aprendizagem, os educandos permanecem fazendo parte do mesmo até o final. Eles se motivam e continuam, não evadindo. Pôde-se averiguar quão importante é o diálogo para a permanência dos educandos em um curso ou disciplina na modalidade a distância
\end{abstract}

Para promover a interatividade, adotamos o grupo do Facebook como principal meio para a interação na disciplina, um grupo para cada polo, reunindo os alunos inscritos na disciplina naquele município. Os alunos se surpreenderam positivamente com o uso do Facebook, pois muitos só conheciam a utilidade das redes sociais para o lazer e a socialização, e não percebiam o potencial para a interatividade e colaboração no contexto educacional. Dessa forma, relataram como essas experiências influenciaram suas práticas enquanto docentes: "Achei interessante, pois com as redes sociais os alunos tendem a interagir mais"; "Achei uma forma espetacular, ajudou-nos na comunicação e interação com os colegas e professores"; "diminuiu a distância entre tutor e alunos"; "Obtive um novo olhar sobre o Facebook"; "Eu amei, pois não tinha ideia de como usar tais ferramentas dentro de uma aula"; "Percebi o quanto podemos trabalhar futuramente na Educação, utilizando os benefícios da Informática. Realizar neste período atividades no Facebook, em grupo e individual, foi de muito valor para minha formação".

\section{ÊNFASE EM AUTORIA E ATIVIDADES PRÁTICAS}

$\mathrm{Na}$ disciplina, em vez de focar em conteúdos a serem estudados pelos alunos, passamos a priorizar as autorias e a realização de atividades práticas efetivadas por meio das Avaliações a Distância (AD). Valorizamos a autoria porque, na cibercultura, produzir e fazer circular informação tornaram-se atos quotidianos, sendo a autoria a característica mais marcante da cultura digital pósmassiva, identificada como o primeiro princípio da cibercultura: a liberação do polo de emissão (LEMOS, 2007). Todos nós nos tornamos autores em potencial: os docentes em suas práticas diárias criam atos de currículo trabalhando em colaboração com os alunos, de forma interativa e dialógica, incentivando-os a se autorizarem, ao mesmo tempo em que os alunos também desenvolvem suas próprias autorias (AMARAL; VELOSO; ROSSINI, 2018).

A valorização das atividades práticas visa a oportunizar a turma vivenciar as práticas da cultura digital, criando oportunidades para o futuro professor aumentar seu letramento digital e se tornar um praticante cibercultural crítico, refletindo e teorizando sobre como educar nossas crianças e jovens 


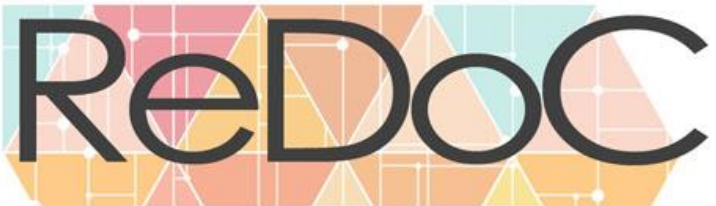

\section{Revista Docência e Cibercultura}

para a sociedade contemporânea. Partimos da premissa de que o professor só faz uso daquilo que conhece, daquilo que está em seu repertório de práticas; pouco adianta discutir o uso da informática na educação apenas na teoria. Isso não significa abrir mão dos conteúdos, muito menos da teorização. Concebemos a realização de atividades práticas como um meio para o aprendizado, como também para incentivar os alunos a estudarem os conteúdos da disciplina, seja para realizarem a atividade em si, seja para se apoiarem na teorização considerando a prática realizada. O objetivo é levar o aluno a realizar o movimento práticateoriaprática (ALVES, 2001).

Em geral, os alunos e os tutores gostaram muito das atividades práticas da disciplina. Vários alunos elogiaram a abordagem: "Realmente só se aprende fazendo!!!"; “As atividades foram bem interativas, úteis e bem construtivas, aliás, a experiência com a disciplina Informática na Educação foi muito positiva e interessante! As atividades foram interessantes, aprendi, interagi e conheci programas, aplicativos e pessoas de outros períodos!"; "Foram atividades que deram oportunidade de conhecimento e crescimento nessa área, eu aprendi muito”.

Solicitamos que os alunos atribuíssem uma nota para a abordagem com ênfase na prática, em vez de uma abordagem mais conteudista-teórica. Apenas um aluno a avaliou como indiferente, e todos os demais a consideraram boa (19\%) ou excelente (79\%). Os professores-tutores também disseram que os alunos gostaram muito das atividades: "muitos dos meus alunos ficaram encantados com o Google Drive e com a História em Quadrinhos."; "Elas [as alunas] relataram ter gostado muito de todas as atividades por serem dinâmicas, atuais e práticas."

Supúnhamos que as atividades práticas motivariam os alunos a estudar os conteúdos da disciplina. Nesse aspecto, identificamos uma divergência entre a opinião dos alunos em comparação com a dos tutores. Enquanto os alunos disseram que as atividades práticas os motivaram a estudar os conteúdos, os tutores relataram que os alunos continuaram a ignorar os conteúdos: "Os alunos não acessam o conteúdo disponibilizado"; "Precisamos conseguir trazer mais teoria... Ainda acho os trabalhos muito no campo do achismo".

Incentivar os alunos a estudarem os conteúdos tem sido um desafio desde o início da disciplina. Mesmo quando eram realizadas provas com base nos conceitos abordados no livro-texto, percebíamos que os alunos tinham pouca compreensão do conteúdo, pois muitas respostas eram superficiais, genéricas ou evasivas. A mudança para uma abordagem mais prática foi, em parte, uma ação para tentar superar essa dificuldade histórica percebida na disciplina. 


\section{Revista Docência e Cibercultura}

\section{AVALIAÇÃO FORMATIVA}

As provas, denominadas Avaliações Presenciais (AP), representavam uma barreira para que pudéssemos valorizar as práticas na disciplina. Sob a forma impressa, as AP impossibilitavam a realização de qualquer prática com o uso da Informática, induzindo a elaboração de questões sobre conteúdos da disciplina, o que induz os alunos a priorizarem o estudo dos conteúdos para conseguir fazer uma boa prova. Essa lógica conteudista-teórica era exatamente o que vínhamos tentando modificar na disciplina. Como as AP têm um peso maior na nota final, alguns alunos nem faziam as $\mathrm{AD}$ e até conseguiam aprovação mesmo sem terem vivenciado qualquer prática oportunizada na disciplina.

No segundo semestre de 2015, solicitamos ao coordenador do curso uma mudança no peso das avaliações: queríamos que as $\mathrm{AD}$ (as avaliações que utilizávamos para fazer as atividades práticas e autorais) passassem a ter mais peso na nota dos alunos. Para a nossa surpresa, não foi permitido mudar os pesos, mas, em contrapartida, foi apresentada a possibilidade de, experimentalmente, abolirmos as AP, como já acontecia no modelo de avaliação adotado em componentes curriculares como 'Estágio Curricular Supervisionado'. Com essa mudança, conseguimos efetivar a avaliação contínua na disciplina, realizada, semanalmente, a cada atividade prática realizada pelo aluno como parte da AD.

Questionamos os alunos como eles avaliaram o fato de não termos as Avaliações Presenciais (AP1 e AP2): apenas 6\% declararam ser indiferentes, e os demais consideraram bom (16\%) ou excelente $(78 \%)$. Estes resultados surpreendem porque indicam que a turma gostou do modelo de avaliação contínua baseado na realização de atividades práticas em vez de provas conteudistas. Contudo, vale ressaltar que esta situação colocou a disciplina em uma situação 'fora da lei'.

\section{TUTORIA ATIVA}

Os professores-tutores presenciais da disciplina se queixavam, com frequência, que poucos alunos procuravam a tutoria presencial, e com isso sentiam-se desvalorizados. Ficar disponível para tirar dúvidas durante uma hora por semana, numa sala do polo na qual poucos alunos apareciam, sempre nos pareceu um desperdício do trabalho docente. Para valorizar o trabalho desse profissional, tentando romper com o modelo de tutoria reativa induzido pelo sistema de EAD, buscamos efetivar uma tutoria ativa em que os professores-tutores mobilizam os alunos para que participem de situações 


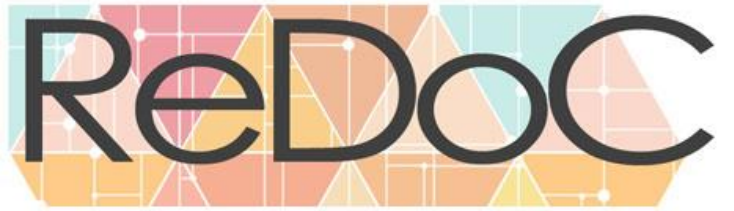

\title{
Revista Docência e Cibercultura
}

de aprendizagem, em que realizam a mediação da conversação do grupo, interagem, provocam, acompanham a participação, procuram os alunos e não ficam apenas esperando por eles. Muitos pesquisadores destacam a importância da atuação docente para a manutenção do aluno nos cursos a distância:

\begin{abstract}
Sabe-se que o trabalho on-line aumenta em até três vezes o tempo de envolvimento de um professor em comparação ao modo presencial de ensino, o que torna muito difícil atender um número elevado de alunos em uma comunidade, mesmo para o mais dedicado educador. Um número muito grande de alunos em uma mesma turma limita, em muito, a capacidade de o professor interagir com os estudantes, um aspecto que deve ser considerado como um ponto de atenção, tendo em vista o descontentamento que a falta de retorno às dúvidas e solicitações dos alunos pode causar, levando-os à desistência. $\mathrm{O}$ retorno constante às suas perguntas e o interesse demonstrado pelo seu desempenho acadêmico fazem com que o aluno sinta-se acompanhado e valorizado em seus esforços de estudo, aumentando suas chances de concluir com êxito sua formação. [...] O relacionamento de confiança efetivado na convivência entre professores, tutores e alunos é fundamental na constituição da segurança do aluno em relação ao curso e à instituição de ensino. As condutas guiadas pela confiança trazem a possibilidade de conversar, conviver em comunidade e de trabalhar em um espaço que tenha significado para todos os envolvidos. Por isso, a qualidade, a frequência e o impacto das interações são determinantes para evitar a evasão dos alunos, já que a crença no curso e nos seus mediadores a distância ajuda a criar uma atmosfera de satisfação e seriedade, fundamentais para dar sentido ao esforço empreendido pelo estudante. (DAUDT; BEHAR, 2013, p.419)
\end{abstract}

Para efetivarmos a mudança do modelo de tutoria, decidimos, no coletivo de professorestutores, modificar as funções atribuídas aos tutores presenciais e a distância. De acordo com o regulamento (FUNDAÇÃO CECIERJ, 2008), cabe ao tutor presencial "estar presente no polo, no horário previsto, para atendimento e orientação dos discentes” (p.7), e cabe ao tutor a distância a mediação online e a promoção da interatividade entre os alunos, sendo "o responsável pela coordenação de fóruns e chats [...], além de propiciar espaços para interação informal entre os estudantes" (p.8).

Essas atribuições dificultavam algumas ações que gostaríamos de realizar na disciplina, como as sessões de bate-papo (chat). Sabemos que uma sessão de bate-papo deve ser realizada em um grupo não muito grande, sendo razoável conter até uns 12 alunos (pois acima disso a conversação fíca confusa demais). Se a cada semestre tínhamos aproximadamente 300 alunos inscritos na disciplina, significava que, para realizar uma única sessão de bate-papo de uma hora, com grupos de 12 alunos, seria preciso 


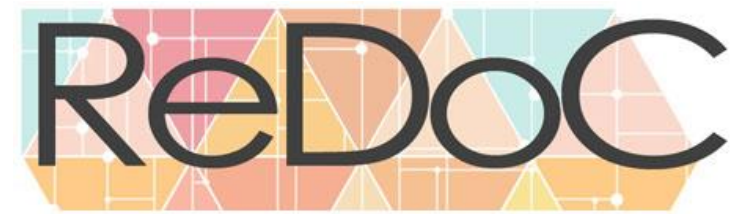

\section{Revista Docência e Cibercultura}

realizar 25 sessões, dando muito trabalho para os 2 professores-tutores a distância. Esse trabalho foi então assimilado pelos 13 professores-tutores presenciais que estavam atuando na disciplina à época em que tomamos essa decisão.

Os professores-tutores presenciais também passaram a realizar parte do trabalho de mediação online, especialmente a criação do grupo no Facebook agregando os alunos do polo na disciplina a cada semestre e efetivando a mediação online naquele grupo. Consideramos que os professores-tutores presenciais devem mediar as conversas entre os alunos de um polo, pois esses profissionais conhecem o município e até conhecem presencialmente alguns dos alunos, e conhecer essas informações são importantes para uma melhor mediação.

Os professores-tutores presenciais apontaram os benefícios em utilizar o grupo do Facebook na disciplina: "favoreceu uma maior aproximação dos alunos e um compartilhamento e trocas de ideias"; "Como tutora, gosto de estar integrada nestes sistemas. Me percebo parte desse mundo digital, conectado".

Com as novas funções, que efetivaram uma tutoria ativa, o professor-tutor presencial passou a ser o principal responsável pela mediação online e pela interatividade dos alunos do polo sob sua responsabilidade, o que deu mais sentido ao seu trabalho docente, sentindo-se mais valorizamos.

\section{CURADORIA DE CONTEÚDOS ONLINE}

A principal fonte de conhecimento de nossa sociedade contemporânea não é mais a biblioteca com seus livros impressos. Hoje, quando queremos aprender algo, geralmente consultamos a web: fazemos uma busca na Google, navegamos no hipertexto da Wikipédia, assistimos a uma videoaula no YouTube, consultamos uma apresentação compartilhada no SlideShare, baixamos um artigo científico, lemos uma notícia num blog ou num jornal online, percorremos as postagens divulgadas pelas páginas e grupos no Facebook e outras redes sociais, entre outras táticas. Virou bordão: o conhecimento está a um clique de distância, na Web, distribuído na rede em múltiplos formatos.

$\mathrm{Na} \mathrm{EAD}$, contudo, ainda predomina a cultura do século passado, em que se acreditava ser necessário desenvolver livros adequados para EAD. Como resultado, muitos cursos têm seu próprio material didático, seus próprios livros, sejam impressos ou disponibilizados em formato digital (geralmente em PDF). 


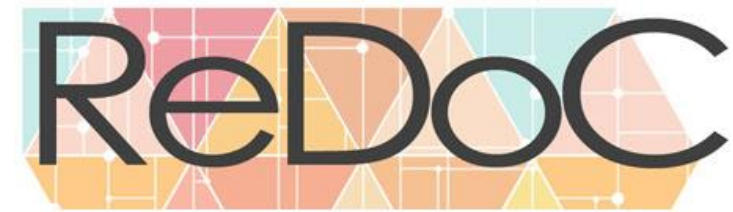

\section{Revista Docência e Cibercultura}

Em nossa disciplina, inicialmente tínhamos um livro-texto desenvolvido por professoresconteudistas. Ao longo dos anos, desenvolvemos a tática da curadoria de conteúdos: processos de escolher e dar visibilidade a determinadas obras, como prática de socialização e mediação de saberes (BASSANI; MAGNUS; WILBERT, 2017). Desse modo, assumimos a responsabilidade de selecionar bons conteúdos, dentre os que circulam na rede (artigos científicos online, videoaula, página na Wikipédia, sites, tutoriais, entre outros), para serem utilizados como referência de estudo. Complementarmente, desenvolvemos roteiros de estudo alinhavando os conteúdos, e propusemos atividades que requeriam colocar em prática e refletir sobre o conhecimento abordado nos conteúdos selecionados.

Com essa estratégia, apoiamos nossos alunos a desenvolverem competência e autonomia para construírem conhecimento a partir dos conteúdos que circulam na rede, em múltiplos formatos, pois consideramos que seja esta a tática mais alinhada com o modo de aprender na sociedade contemporânea.

Por ser diferente do que se costuma praticar na EAD, poderíamos supor que a curadoria de conteúdos online provocaria resistência ou dificuldade para os alunos e professores-tutores. Contudo, ao perguntarmos como os alunos avaliaram o fato dos conteúdos estarem todos online em vez de impressos, a grande maioria julgou como bom (34\%) ou excelente (52\%), sendo que somente $10 \%$ dos alunos consideraram indiferente, e apenas três alunos consideraram ruim. Este é um dado revelador, pois indica que os alunos aceitam e até preferem que os conteúdos estejam online, distribuídos gratuitamente na rede e nem precisam ter sido desenvolvidos especificamente para a disciplina na modalidade a distância, o que contraria muito do que ainda se acredita e se pratica na EAD.

Muitos alunos ressaltaram a facilidade de os conteúdos estarem todos online: "Gostei muito pela praticidade e facilidade de acesso."; "Achei ótimo, é mais prático e nem por isso menos importante. Temos oportunidade de buscar informações e isso amplia e muito nossa bagagem de conhecimento". De fato, os conteúdos tiveram alta aprovação dos alunos e dos professores-tutores. Graças à curadoria de conteúdos, passamos a ter flexibilidade para atualizar os conteúdos da disciplina a cada semestre, sem 'parar no tempo' como havia acontecido com o livro-texto. 


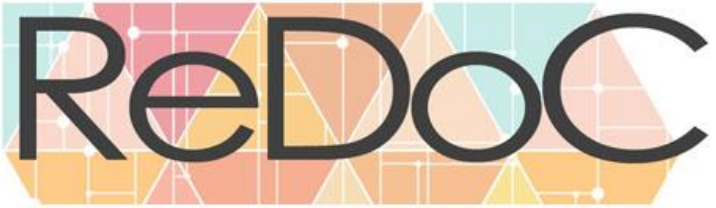

Revista Docência e Cibercultura

\section{CONSIDERAÇÕES FINAIS}

Os princípios discutidos neste artigo explicam as ações que foram realizadas na disciplina em busca de um desenho didático com inspirações na cibercultura, o que denominamos de Educação Online para diferenciar das práticas massivas e instrucionistas da Educação a Distância. Tais ações representam o resultado de tentativas de mudanças experimentadas ao longo de 20 edições da disciplina, fruto de uma pesquisa-ação que teve como ponto de partida a insatisfação com o modelo instrucionista-massivo induzido pelo sistema de EAD comparado com algumas experiências anteriores com Educação Online.

As mudanças na disciplina foram efetivadas com apoio de todos: administração, coordenador de curso, professores-tutores e alunos da disciplina, num processo de construção coletiva, negociações, conquistas, ousadias e subversões. Após uma década de sucessivas ações buscando reconfigurar a disciplina, consideramos ter chegado em um desenho didático adequado, efetivando as mudanças que foram possíveis considerando estarmos em um sistema de EAD, nos valendo de algumas táticas instituintes, ao criarmos nossos atos de currículo (CERTEAU, 1994).

Subvertemos algumas normas. Abolimos as provas (AP) e valorizamos o processo de descoberta por meio de atividades práticas, o que possibilitou outras formas de aprendizado e potencializou o desenvolvimento de autorias docentes e discentes. Essa ação também nos possibilitou efetivarmos uma avaliação formativa. Definimos novas atribuições para os professores-tutores presenciais, que passaram também a fazer a mediação online, com vistas a uma tutoria ativa, com ênfase na interatividade e na colaboração. Sem nos limitamos ao AVA do curso, passamos a utilizar diversos sistemas computacionais para efetivar atividades inspiradas nas práticas da cibercultura, visando a promover uma aprendizagem significativa. Não adotamos um livro-texto, mas sim conteúdos disponíveis na web. Também buscamos promover muita interatividade entre os alunos (para além da interatividade que usualmente já se estabelece entre o aluno e o professor-tutor).

Cabe destacar que alguns princípios colocados em ação na disciplina são interdependentes: o apoio dos professores-tutores presenciais para efetivar uma tutoria ativa tornou possível valorizar as atividades práticas com uso de variados sistemas computacionais, promovendo mais interatividade e colaboração entre os alunos. As atividades práticas e autorais, por sua vez, foram mais valorizadas somente após abolirmos as provas da disciplina. 


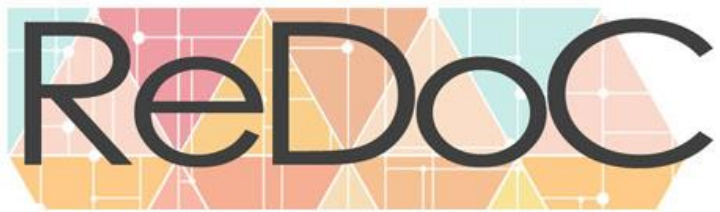

\section{Revista Docência e Cibercultura}

Com essas ações, ficamos fora da lei por abolirmos as provas presenciais, e aumentamos a carga de trabalho dos professores tutores presenciais que não receberam a mais para exercer as novas funções. Essas transgressões, efetivadas com o empenho de todos, denunciam a necessidade de mudanças no sistema de EAD de nosso país para que desenhos didáticos alternativos possam ser efetivados, como já havia sido apontado por Lapa e Pretto (2008). Por exemplo, por questões orçamentárias, as disciplinas do $5^{\circ}$ período em diante, do curso em questão, não dispõem de professores-tutores presenciais; contudo, entendemos que educação requer mediação docente e sem tais profissionais não seria possível efetivar as práticas que desejávamos em nossa disciplina - em vez de dispensar esse profissional, consideramos que é preciso valorizá-los mais, ao contrário do que vem sendo geralmente efetivado na EAD.

Por fim, espero que, com o caso que relatei sobre a busca pela efetivação de um desenho didático inspirado em práticas da cibercultura, em uma disciplina ofertada na modalidade a distância, suscite mudanças políticas no sistema de EAD de nosso país, bem como inspire outros professores a repensar o desenho didático e suas práticas na modalidade a distância.

\section{REFERÊNCIAS}

ALVES, Nilda. Decifrando o pergaminho: o cotidiano das escolas nas lógicas das redes cotidianas. In: OLIVEIRA, Inês B.; ALVES, Nilda (Org.). Pesquisa nos/dos/com os cotidianos das escolas: sobre redes de saberes. Petrópolis, RJ: DP et Alii, 2001, p. 13-38.

AMARAL, Mirian M. Autorias textuais e imagética em redes de aprendizagem online produções docentes e discentes. Novas Edições Acadêmicas, 2016.

AMARAL, Mirian Maia; VELOSO, Maristela Midlej Silva de Araujo; ROSSINI, Tatiana Stofella Sodré. A autoria coletiva no contexto da educação em tempos de cibercultura. Sociedade Brasileira de Computação, 2018. (Série Informática na Educação). Disponível em: $<$ http://ieducacao.ceie-br.org/autoriacoletiva>

BARBIER, René. A pesquisa-ação. Brasília: Liber Livro Editora, 2007.

BASSANI, Patrícia Scherer; MAGNUS, Emanuele Biolo; WILBERT, Berta. A curadoria digital online e o processo de formação do professor-autor: experiências de autoria em/na rede. Interfaces Científicas-Educação, v. 6, n. 1, p. 93-106, 2017.

BELLONI, Maria L. Educação a distância. 6. ed. Campinas, SP: Autores Associados, 2012. 


\section{Revista Docência e Cibercultura}

BRASIL. Ministério da Educação. Decreto Federal no . 5.622, de 19 de dezembro de 2005.

Regulamenta o art. 80 da Lei $\mathrm{n}^{\circ}$. 9.394, de 20 de dezembro de 1996, que estabelece as diretrizes e bases da educação nacional. Disponível em:

<http://www2.mec.gov.br/sapiens/portarias/dec5622.htm>. Acesso em: 30 abr 2018.

CASTELLS, Manuel. A sociedade em rede. São Paulo: Paz e Terra, 1999.

CERTEAU, Michel de. A invenção do cotidiano: 1. artes de fazer. Petrópolis, RJ: Vozes, 1994.

CORTELLA, Mário Sergio; DIMENSTEIN, Gilberto. A Era da Curadoria: o que importa é saber o que importa! (Educação e formação de pessoas em tempos velozes). Campinas, SP: Papirus 7 Mares, 2015.

DAUDT, Sônia I. D.; BEHAR, Patricia A. A gestão de cursos de graduação a distância e o fenômeno da evasão. Educação (Porto Alegre, impresso), v. 36, n. 3, p. 412-421, set./dez. 2013.

FAGUNDES, Léa C.; SATO, Luciane S.; LAURINO, Débora P. Aprendizes do futuro: as inovações começaram! Coleção Informática para a mudança na Educação. Brasília, MEC, 1999. Disponível em: 〈http://www.dominiopublico.gov.br/download/texto/me003153.pdf〉 Acesso em: 02 abr. 2018.

FAVERO, Rute V. M. Dialogar ou evadir: Eis a questão!: um estudo sobre a permanência e a evasão na educação a distância. Dissertação (Mestrado em Educação), Universidade Federal do Rio Grande do Sul, Porto Alegre, 2006.

FUKS, Hugo et al. Teorias e modelos de colaboração. In: PIMENTEL, Mariano; FUKS, Hugo (Org.) Sistemas Colaborativos. Rio de Janeiro: Elsevier, 2011, p.16-33.

FUNDAÇÃO CECIERJ. Funções e atribuições vinculadas ao Consórcio CEDERJ. Rio de Janeiro, 2008 [Documento interno].

LAPA, Andrea; PRETTO, Nelson De Luca. Educação a distância e precarização do trabalho docente. Em Aberto, Brasília, v. 23, n. 84, p.79-97, nov. 2010.

LEMOS, A. Cibercultura como território recombinante. In: MARTINS, C. D. et al. (Org.) Territórios recombinantes: arte e tecnologia - debates e laboratórios. São Paulo: Instituto Sérgio Motta, 2007. p.35-48.

LÉVY, Pierre. As tecnologias da inteligência. Rio de Janeiro: Ed.34, 1993.

LÉVY, Pierre. Cibercultura. Rio de Janeiro: Ed.34, 1999.

LUCENA, Carlos J. P.; FUKS, Hugo. Tecnologias de Informação Aplicadas à Educação (TIAE): Manual do Aprendiz. Rio de Janeiro: PUC-Rio, 2002. 


\section{Revista Docência e Cibercultura}

MACEDO, Roberto S. Atos de currículo e autonomia pedagógica: o socioconstrucionismo curricular em perspectiva. Petrópolis, RJ: Vozes, 2013.

MARQUES, Aline M.; PIMENTEL, Mariano; SIQUEIRA, Sean W. M. Aprendizagem colaborativa baseada em projeto com o uso de blog: relato de uma experiência na Licenciatura em Pedagogia a distância. In: MORAES, Marco A.; OLIVEIRA, Olívia C. (Org.). Tecnologia, linguagens e educação: buscando diálogos, partilhando experiências. Seropédica - RJ: Ed. UFRRJ, 2011, p. $30-40$.

NICOLACI-DA-COSTA, Ana Maria; PIMENTEL, Mariano. Sistemas colaborativos para uma nova sociedade e um novo ser humano. In: PIMENTEL, M.; FUKS, H. (Org.). Sistemas colaborativos. Rio de Janeiro: Elsevier, 2011. p. 3-15.

RIBEIRO, Mayra R. F.; CARVALHO, Felipe S. P.; SANTOS, Rosemary. Ambiências híbridasformativas na educação online: desafios e potencialidades em tempos de cibercultura. Revista Docência e Cibercultura, v. 2, n. 1, p. 1-13, 2018.

SANTAELLA, Lucia. Comunicação ubíqua: repercussões na cultura e na educação. Pia Sociedade de São Paulo-Editora Paulus, 2014.

SANTOS, Edméa Oliveira; CARVALHO, Felipe Silva Ponte; PIMENTEL, Mariano. Mediação docente online para colaboração: notas de uma pesquisa-formação na cibercultura. ETDEducação Temática Digital, v. 18, n. 1, p. 23-42, 2016.

SANTOS, Edméa. Educação online para além da EAD: um fenômeno da cibercultura. In: SILVA, Marco; PESCE, Lucila; ZUIN, Antonio (Org.). Educação online: cenário, formação e questões didático-metodológicas. Rio de Janeiro: Wak Ed, p. 29-48, 2010.

SANTOS, Edméa; SILVA, Marco. O desenho didático interativo na educação online. Revista Iberoamericana de Educación, v. 49, p. 267-287, 2009.

SANTOS, Rosemary; RIBEIRO, Mayra R.F., CARVALHO, Felipe S.P. Educação Online: aprenderensinar em rede. Sociedade Brasileira de Computação, 2018. (Série Informática na Educação). Disponível online: 〈http://ieducacao.ceie-br.org/educacaoonline/>

SIEMENS, George. Uma breve história da aprendizagem em rede. 2008. Disponível em <https://pt.slideshare.net/augustodefranco/uma-breve-historia-da-aprendizagem-em-rede>. Acesso em: 02 abr. 2018.

SILVA, Marco. Paulo Freire, Vygotsky, Freinet, Dewey e Anísio Teixeira usariam o WhatsApp! In: PORTO, Cristiane; OLIVEIRA, Kaio E.; CHAGAS, Alexandre. Whatsapp e educação: entre mensagens, imagens e sons. Salvador: EDUFBA, 2017, p.15-26. 


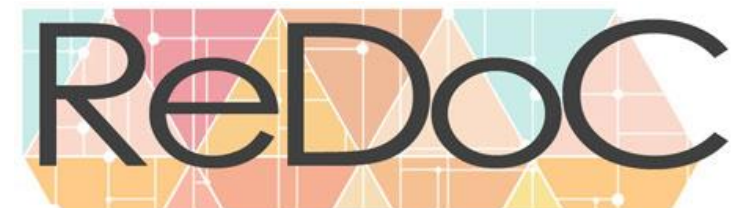

Revista Docência e Cibercultura

SILVA, Marco. Sala de aula interativa. 2. ed. Quartet: Rio de Janeiro, 2000. [6 ed., São Paulo: Edições Loyola, 2012].

TORRES, Patrícia L.; IRALA, Esrom A. F. Aprendizagem colaborativa: teoria e prática. In: TORRES, Patrícia L. (Org.) Complexidade: redes e conexões na produção do conhecimento [Coleção Agrinho]. Curitiba: SENAR - PR, 2014. p.61-94. 